\title{
RESILIÊNCIA EM PAIS QUE CUIDAM DE CRIANÇAS DIAGNOSTICADAS COM TRANSTORNO DO ESPECTRO AUTISTA
}

\section{RESILIENCE AMONG PARENTS CARING FOR CHILDREN DIAGNOSED AS HAVING AUTISTIC SPECTRUM DISORDER}

\author{
Heitor Augusto Colli Trebien* \\ Ariadne Fadel Afornali Depine ${ }^{* *}$ \\ Tatiany Honório Porto ${ }^{* *}$ \\ Rosana Angst Pasqualotto ${ }^{* * * *}$
}

\begin{abstract}
RESUMO
O objetivo desta pesquisa foi identificar como ocorre o processo de resiliência nos pais que possuem uma filha diagnosticada com Transtorno do Espectro Autista, analisando os fatores de risco, de proteção e estratégias de enfrentamento. Para isso, foi realizada uma entrevista com os pais de uma criança autista sobre suas dificuldades e facilidades no cuidado de sua filha com tal diagnóstico. Os resultados indicam que existem muitos obstáculos no percurso do tratamento da filha, como julgamentos externos que prejudicam a forma como a mãe se sente, culpa sobre o diagnóstico e problemas financeiros. No entanto, também foi verificado que existem formas de superar essas dificuldades, através do posicionamento dos pais sobre a situação. Com isso, o estudo concluiu que a rede de apoio social, o sistema público e as escolas são excelentes mecanismos, que tem a função de auxiliar na superação das dificuldades encontradas.
\end{abstract}

Palavras chave: Resiliência, Pais, Transtorno do Espectro Autista, Fatores de Risco, Fatores de Proteção.

\begin{abstract}
The objective of this study was to identify how the process of resilience occurs among parents with a child diagnosed as having Autistic Spectrum Disorder, analyzing risk and protection factors and coping strategies. To this end, was conducted an interview which the parents talk about their difficulties and strengths in caring for her daughter who has the Autistic Sprectrum Disorder diagnosis. The results indicate many obstacles in the process of her daughter's treatment, such as outside judgements that undermine how the mother feels about herself, guilt with regard to the diagnosis and financial problems. On the other hand, the mother's position about the situation showed that ways do exist for overcoming these difficulties. As a result, the study concluded that the social support network, the public system and schools are excellent mechanisms and serve to assist in overcoming the difficulties encountered.
\end{abstract}

Keywords: Resilience, Parents, Autism Spectrum Disorder, Risk Factors, Protective Factors.

\footnotetext{
* Psicólogo formado pela Pontifícia Universidade Católica do Paraná. heitor.trebien@gmail.com

${ }^{* *}$ Estudante de Graduação da Pontifícia Universidade Católica do Paraná. ariadnefadel@hotmail.com

*** Psicóloga formada pela UNIFIL, mestre em Análise do Comportamento pela UEL e doutora em Psicologia Experimental pela USP. Professora da Pontifícia Universidade Católica do Paraná. taty.porto@gmail.com

**** Psicóloga formada pela PUCPR, Especialista em Formação Pedagógica do Professor Universitário pela PUCPR, Mestre e Doutoranda em Educação Pela UFPR. Professora do CESCAGE e Professora Colaboradora da UEPG. roangst@gmail.com
} 


\section{INTRODUÇÃO}

O autismo é caracterizado por três fatores, que são: as dificuldades nas áreas de interação social, comunicação verbal e não verbal e o desenvolvimento de interesses. Vale salientar que, apesar da similaridade dos sintomas do espectro autista, em cada indivíduo há particularidades específicas (TAMANAHA; PERISSINOTO; CHIARI, 2008).

No Manual Diagnóstico e Estatístico de Transtornos Mentais V - DSM 5 (AMERICAN PSYCHIATRIC ASSOCIATION, 2014) e na CID-11 o espectro autista se enquadra em um transtorno do neurodesenvolvimento, sendo identificado por "espectro" graças à variabilidade de acordo com a idade cronológica, o nível de desenvolvimento e da gravidade da condição do autista. Deve-se levar em conta que os sintomas podem ser observados aproximadamente entre os 12 e 24 meses de idade ( 1 a 2 anos). Dependendo da gravidade, os sintomas aparecem antes dos 12 meses. Esse transtorno acomete 4 vezes mais homens do que mulheres, e outras comorbidades podem estar associadas, como o TDAH (Transtorno de Déficit de Atenção e Hiperatividade) e o Transtorno do Desenvolvimento Intelectual. De acordo com o DSM V (2014), há três níveis de gravidade (Nível 1, Nível 2 e Nível 3) com 5 critérios diagnósticos (A, B, $\mathrm{C}, \mathrm{D}$ e E) $)^{1}$. o referido manual explica que os sintomas básicos são: déficits na reciprocidade socioemocional, déficits nos comportamentos comunicativos não verbais, déficits para desenvolver, manter e compreender relacionamentos, movimentos motores com uso de objetos e fala estereotipados e repetitivos, adesão inflexível a rotinas, interesses fixos altamente restritos, hiper ou hiporreatividade a estímulos sensoriais. Tudo isso pode prejudicar a relação da criança com os pais, assim como o educador deve ter em vista técnicas e práticas para ajudar a criança e a família.

Gadia, Tuchman e Rotta (2004) sugerem que o neurodesenvolvimento da criança autista possui um padrão anormal, "com um crescimento acelerado durante os primeiros anos de vida seguido por uma desaceleração em algumas regiões do cérebro, enquanto em outras há uma parada do crescimento" (GADIA; TUCHMAN; ROTTA, 2004, p. S87). Por possuir um desenvolvimento neuronal prejudicado, pode haver

\footnotetext{
${ }^{1}$ Para maiores informações, ler o Manual Diagnóstico e Estatístico de Transtornos Mentais V, de 2014, conhecido como DSM V.
}

como consequência para a criança uma dificuldade no reconhecimento de faces (giro fusiforme), na diferenciação de expressões faciais (giro temporal superior e médio), na interação social e no relacionamento afetivo, graças a diferenciação de áreas como o córtex pré-frontal e a amígdala no desenvolvimento autista (GADIA; TUCHMAN; ROTTA, 2004).

Esses obstáculos característicos do diagnóstico de Transtorno do Espectro Autista podem levar a problemas nas relações familiares. Sobre isso, Lietz et al. (2016) destacam a importância da resiliência familiar - processo onde a família supera as adversidades advindas do processo de cuidar. Para os autores, é normal surgirem conflitos familiares, sendo necessário procurar formas de solucionar os efeitos negativos advindos desses conflitos.

Sabe-se que cuidadores de crianças autistas passam por muitas dificuldades intrafamiliares na interação com a criança. Como essas crianças pensam e se relacionam de formas diferentes, há a probabilidade de que membros da família não aceitem a forma de se comunicar da criança. Um dos principais fatores estressores na saúde mental dos pais é a não aceitação social e familiar da criança. Muitos desses pais acabam ficando isolados, não realizando atividades diárias que gostariam. Ainda no mesmo estudo, afirmam que há outros fatores que influenciam o estresse, como a severidade do autismo, a condição social e de trabalho, questões culturais e a dificuldade de acesso a serviços especiais voltados para a criança (BARBOSA; FERNANDES, 2009).

As adversidades citadas anteriormente remetem ao conceito de resiliência, que de acordo com Juliano e Yunes (2014), é a habilidade de indivíduos e grupos resistirem e superarem situações adversas. A resiliência, portanto, é a transformação positiva de indivíduos e grupos frente a traumas e eventos estressantes da vida. Deve-se ressaltar que é através da percepção que o indivíduo identifica o que é aversivo, demonstrando que resiliência está interligado com o conceito de subjetividade.

A análise do constructo resiliência engloba a interação entre fatores de risco e proteção. O primeiro conceito procura investigar como eventos traumáticos afetam a pessoa. Analisa assim as consequências de condições aversivas, levando em consideração a quantidade de situações negativas que a pessoa foi exposta, a etapa do desenvolvimento em que se encontrava, por 
quanto tempo ficou exposta e a intensidade da experiência vivida. O segundo conceito investiga situações que aliviam uma situação estressora e que facilitam o processo de superação de eventos aversivos. Outro tema importante é o coping, ou estratégia de enfrentamento, que se refere à capacidade individual ou grupal de se utilizar recursos cognitivos, comportamentais e emocionais para elaborar o trauma (JULIANO; YUNES, 2014).

Diante do acima exposto, o objetivo deste estudo é compreender como a resiliência se dá em âmbito familiar, na relação entre pais e sua filha diagnosticada com o Transtorno do Espectro Autista.

\section{MÉTODO}

O presente trabalho é um estudo de caso, que de acordo com Yin (2015) é um tipo de pesquisa que investiga um fenômeno em seu contexto real e pode incluir casos únicos ou múltiplos.

\section{Participantes:}

Os participantes do presente trabalho foram pais de uma filha diagnosticada com transtorno do espectro autista. A amostra da pesquisa foi por conveniência, e foi indicado, pela rede de conhecidos dos autores, pais que possuíam uma filha com o diagnóstico de autismo.

\section{Local:}

O local de realização foi o domicílio dos entrevistados. os autores entraram em contato com a família e ficou definido que o melhor local para os entrevistados seria a própria residência.

\section{Instrumentos:}

Foi elaborado um roteiro de entrevista semiestruturado pelos autores, onde foram levantados os dados sociodemográficos da família, e treze perguntas foram feitas. As perguntas foram: 1. Quais foram os primeiros indícios do espectro autista que apareceram na criança?; 2. Como foi realizado o diagnóstico?; 3. Quem os auxiliou nos momentos mais difíceis com relação ao diagnóstico do filho?; 4. Como a instituição clínica ajuda no cuidado da criança?; 5. Como o diagnóstico de autismo mudou a rotina do casal?; 6 .
Como o casal concilia o trabalho e o cuidado com o filho?; 7. Quais as principais dificuldades da criança na escola?; 8. A educação da criança tem auxiliado na comunicação e no cuidado com ela?; 9. Quais as potencialidades que vocês identificam na criança?; 10. Há formas específicas de se comunicar com ela? Se sim, como as realiza?; 11. Que tipo de atividades de lazer a família realiza?; 12. O que é feito para lidar com as dificuldades advindas do diagnóstico do seu filho?; 13. Há algo que desejam acrescentar sobre a temática abordada nesta entrevista?

\section{Procedimentos:}

O projeto foi encaminhado para o Comitê de Ética (CEP) da PUCPR e aprovado sob parecer 1.455.819. Após aprovação, uma mãe foi contatada e convidada a participar da pesquisa. Com a aceitação do Termo de Consentimento Livre e Esclarecido (TCLE), e a entrevista foi realizada com os pais da criança diagnosticada com autismo e gravada com a autorização dos participantes. Esta ocorreu na casa destes, foi realizada por dois autores do presente trabalho, e teve a duração de $1 \mathrm{~h}$ e 20 minutos.

Os dados da pesquisa foram interpretados, sistematizados e categorizados de acordo com a proposta conceitual da Análise de Conteúdo. De acordo com Bardin (1994) a Análise de Conteúdo é definida como uma técnica que permite analisar e compreender sistemática e objetivamente a linguagem em diversos meios e situações. A partir dessa coleta de dados, pôde-se inferir uma estrutura básica da comunicação, esclarecendo o que aquela mensagem significa naquele contexto, sendo elas divididas em categorias e subcategorias.

\section{RESULTADOS E DISCUSSÃO}

O núcleo familiar é composto por 5 integrantes: L. de 7 anos, com Transtorno do Espectro Autista, uma irmã mais nova de 4 anos (i1) e outra mais velha (i2) com 9 anos. Os pais P. (pai), com 37 anos e V. (mãe) com 42 anos são casados há aproximadamente 13 anos. Ambos possuem nível superior completo com pós-graduação. São provenientes de BP (nome de cidade fictício, para garantir o sigilo de pesquisa) e moram em Curitiba-PR há 7 anos. A mãe é professora da rede estadual de ensino de Curitiba-PR, trabalha 
aproximadamente 40 horas semanais, e o pai é policial militar, afastado por licença médica e fica período integral em casa.

De acordo com V., até os 2 anos, L. foi uma criança normal, apenas apresentava uma fala que era bem reduzida, com baixa interação com os colegas. Percebiam que a menina expressava alguns comportamentos repetitivos, como se ela estivesse realizando um "ritual" (SIC). A garota pegava nas "Poli's" - um tipo de boneca pequena - e brincava apenas com esse tipo de boneca, ela não brincava com outros brinquedos ou bonecas maiores. Essas brincadeiras eram feitas sozinha, sem interação com a irmã mais velha (i2).

A partir disso, os pais decidiram procurar por ajuda médico-pediatra, e a opinião geral que ouviam era: "é um ritmo diferente..." (SIC). Decidiram então, ir para Curitiba para ter uma avaliação com uma neurologista, em que foram realizados vários exames.
Inicialmente o exame foi feito para verificar se não havia um problema de audição, como este não estava presente, a neurologista os encaminhou para uma avaliação com uma psicóloga. Dentro de 3 meses, ela deu o diagnóstico de que L. possuía as características do Transtorno do Espectro Autista. Nessa época, L. tinha 3 anos.

Para analisar as respostas da entrevista, utilizou-se a Análise de Conteúdo. Bardin (1994) explica que a análise de conteúdo é definida como uma técnica que permite analisar e compreender sistemática e objetivamente a linguagem em diversos meios e situações. A partir da coleta de dados, pode-se inferir uma estrutura básica da comunicação, esclarecendo o que aquela mensagem significa naquele contexto, sendo encontradas categorias e subcategorias de análise. Foram encontradas três categorias e 24 subcategorias, que podem ser vistas no Quadro 1.

Quadro 1: Categorias e subcategorias encontradas de acordo com a análise de conteúdo de Bardin.

\begin{tabular}{|c|c|}
\hline \multicolumn{2}{|c|}{ Categorias e Subcategorias que Influenciam o Desenvolvimento da Resiliência } \\
\hline Fatores de proteção & $\begin{array}{l}\text {-Acreditar no sistema público de ensino } \\
\text {-Percepção de desenvolvimento da filha -Presença dos pares } \\
\text {-Rede de amigos que aceitam L. } \\
\text {-Relacionamento familiar comunicativo } \\
\text {-Religiosidade } \\
\text {-Tempo exclusivo para o casal } \\
\text {-Ter atendimento psicológico } \\
\text {-Ter um ambiente escolar propício }\end{array}$ \\
\hline Fatores de risco & $\begin{array}{l}\text {-Culpa sobre o diagnóstico da filha } \\
\text {-Sistema Educacional não adaptado } \\
\text {-Falta de Suporte do Sistema Público local } \\
\text {-Estresse Familiar } \\
\text {-Dificuldades financeiras } \\
\text {-Julgamento externo preconceituoso sobre o Indivíduo com TEA } \\
\text {-Isolamento Social } \\
\text {-Falta de Rede de Apoio } \\
\text {-Ausência de pares }\end{array}$ \\
\hline Estratégias de enfrentamento & $\begin{array}{l}\text {-Capacidade de solucionar problemas -Visão positiva da vida } \\
\text {-Buscar estratégias adaptadas às necessidades dos filhos } \\
\text {-Aceitar os próprios limites } \\
\text {-Mudança de cidade } \\
\text {-Desenvolvimento profissional a partir do contato com o TEA. }\end{array}$ \\
\hline
\end{tabular}

Fonte: Os autores.

A seguir serão apresentadas de forma mais detalhada cada uma das categorias e subcategorias encontradas.

\section{FATORES DE PROTEÇÃO}

Os Fatores de Proteção identificados foram acreditar no sistema público de ensino, percepção de desenvolvimento da filha, presença dos pares, rede de amigos que aceitam L., relacionamento familiar 
comunicativo, religiosidade, tempo exclusivo para o casal, ter atendimento psicológico, ter um ambiente escolar propício.

Para Noronha et al. (2009) o fator de proteção envolve tanto a condição em que o sujeito está inserido quanto como os relacionamentos são construídos socialmente. $\mathrm{O}$ fator de proteção identificado como acreditar no sistema público de ensino reflete em como os relacionamentos de $\mathrm{V}$. foram construídos socialmente. Por ser professora de escola pública, a mãe procurou matricular suas filhas nesse tipo de instituição, afirmando:

V: $[\ldots]$ e eu sempre acreditei nas escolas públicas, então a minha opção já foi desde o início em escola pública, tanto que a gente nem buscou aqui escola particular, porque eu disse - não, eu quero que ela, eu sou professora de escola pública eu tenho que acreditar, por mais que né, não tenhamos aí as melhores condições mas, então elas vão estudar numa escola pública também, e... Foi nossa assim, digo mirei no que vi acertei no que não vi, porque fui abençoada essa escola ele é muito assim receptiva sabe? Então, a pedagoga, o pessoal e a equipe sempre prontos, a gente marca, pede alguma coisa à [clínica particular de Curitiba especializada no atendimento à criança autista], têm um contato direto com a escola e também tem um apoio de professores [...] nesse ponto, está muito bem.

Em relação ao fator de proteção percepção de desenvolvimento da filha se refere ao que Noronha et al. (2009) explicam: os fatores de proteção têm caráter subjetivo, o que irá influenciar na forma como a pessoa resolve seus problemas, procurando amenizar aspectos negativos da situação.

V: Por isso que é muito importante a informação para... porque o autista a gente sabe que ele dá conta, se ele for estimulado ele absorve, [...] a dificuldade de interação social sempre vai existir, então assim será que a L. vai namorar, vai casar? Já não sei, não sei se vai ser do interesse dela, mas que ela vai ser inserida no mercado de trabalho, vai namorar, vai viver normalmente, isso a gente não tem dúvida.

O fator de proteção presença dos pares se relaciona com o que Juliano e Yunes (2014) explicam sobre rede de apoio social e afetiva, entendendo que relacionamentos sociais melhoram a qualidade de vida da pessoa, permitindo que o sujeito supere suas dificuldades com maior facilidade. A interação social abre oportunidade para que o indivíduo procure por ajuda, o que facilita a construção de estratégias de enfrentamento.

V: “Quando eu vim na [clínica particular de Curitiba especializada no atendimento à criança autista], tem um clube, um encontro de mães que eles fazem assim, pra gente conversar, enfim, achei bem interessante por que a gente vê - opa, então era por isso! - ou - isso que acontece comigo, não é só comigo, acontece com outras mães também".

O fator de proteção redes de amigos que aceitam L. segue a mesma lógica do fator de proteção presença dos pares. Assim, Juliano e Yunes (2014) explicam que ter uma rede de convivência significativa permite que a pessoa crie um sentimento de pertencer a algum lugar. Dessa forma, V. percebe que sua filha L. tem um futuro e que a menina pode se desenvolver de forma saudável e mais feliz.

\begin{abstract}
$\mathrm{V}:[\ldots]$ a gente vai com uma frequência e as crianças também acolhem a L. [...] incluem a L. na brincadeira e respeitam a $L$. se ela não quer, também não tem problema ela ficar ali, mas ela não fica excluída né, é isso que eu também acho interessante né, porque às vezes pode tá numa né, vamos brincar só nós aqui e ela não entende, então ela fica ali, não a L. também, vamos brincar, corre L., vamos aqui vamos ali.
\end{abstract}

$\mathrm{O}$ fator de proteção relacionamento familiar comunicativo se refere ao que Poletto, Wagner e Koller (2004) explicam sobre as categorias de atividades diárias e do relacionamento com a família nuclear. As autoras observaram que muitas crianças cuidam dos próprios irmãos, desenvolvendo um sentimento de responsabilidade com o irmão(a) mais novo(a). Isso permite construir um relacionamento familiar de melhor qualidade, o que foi observada a relação de L. com a irmã.

V.: a i2 sempre foi suporte pra L. na escola por exemplo né, por lá era um ambiente, que eu não podia ficar, e nem pai, então a escola: A L. teve tal comportamento que que faz? i2 vem cá né. i2 era o suporte né. Tudo que não sabiam interpretar chamavam a i2. Isso ajudava bastante porque senão, ela não conseguia se expressar. E ficava nervosa né, e... como que vai fazer? Então a i 2 dava um suporte, só que a gente também tomo bastante cuidado pra i2 ser só irmã né 
O fator de proteção religiosidade se relaciona com o que Leal, Röhr e Júnior (2010) explicam sobre espiritualidade, entendendo esse conceito como o desenvolvimento de valores humanos, que o permite transcender as dificuldades vividas. É pela espiritualidade, segundo os autores, que o ser humano se responsabiliza por seus problemas, para posteriormente resolvê-los. Essa pareceu ser uma estratégia utilizada pela família para lidar com as adversidades diárias.

V.: só aprende quando é pai e mãe, mas é uma responsabilidade muito grande ter filhos, então a gente tem 3, e a terceira nos veio aí brindar com várias situações, mas é de provação a gente agradece a Deus por ter a aquela coisinha maravilhosa ali nos ensinando um montão, e saber que você é responsável pelo o que ele vai ser amanhã.

O fator de proteção tempo exclusivo para o casal se relaciona com o que Sousa (2006) explica sobre o funcionamento do subsistema conjugal, em que o casal constrói uma identidade própria. Assim, há uma relação de complementaridade com coadaptarão entre o marido e a mulher, de forma a proporcionar ao casal satisfação de suas necessidades psicológicas, além de proteção a agentes externos, criando um limite, uma singularidade própria do amor conjugal.

V.:é... poucas as vezes que a gente sai sem elas né, mas a gente já, em comemoração pelos 10 anos de casados, a gente ficou um final de semana né, fomos para um resort e tal, ficamos sem elas e só que aí a gente se vê falando delas o tempo todo né, como todo pai - ai se elas tivessem aqui. Mas sai a gente vai ao cinema. Com o vô e a vó elas ficam bem. Então, mas a gente faz assim... com uma certa regularidade, não dá pra dizer que é uma vez por mês mas a gente sai ou vai jantar ou vai ao cinema, é temos ou às vezes vamos jantar com um amigo né, então temos os nossos também, porque a gente tem que ter como casal também, se não a gente fica 24 horas com elas né

O fator de proteção ter acesso a atendimento psicológico se relaciona com o que Juliano e Yunes (2014) chamam de rede de apoio social e afetiva. Assim, o componente afetivo se refere a formação de vínculos, em que o indivíduo recebe auxílio emocional e reconhecimento nas relações que estabelece. Isso permite formar uma base para os problemas futuros, como descreve a mãe de L.
V.: E aí na busca da psicóloga também, até por conta da formação, ela sempre dizia: "e você, como é que você está? Está tudo bem?

O fator de proteção ter um ambiente escolar propício diz respeito ao que Poletto e Koller (2008) explicam sobre a escola ser um ambiente desenvolvimental, ou seja, é o local onde a criança irá se socializar, aprender comportamentos, regular emoções, desenvolver habilidades sociais, ampliar sua capacidade de atenção e aperfeiçoar uma diversidade de comportamentos.

V.: a professora pega na mão, então assim isso, vem sendo esse carinho da turma né com ela e... o respeito né, acho isso fantástico, porque ela, é realmente uma inclusão, por mais que falte algum tutor, falta isso, mas essa questão da socialização acontece de uma forma fantástica né, porque aí os alunos respeitam as dificuldades dela, os "pitis" aí né, os momentos de frustração, que se irrita, que chora e que grita, mas respeitam que ela tem essa diferença né

\section{FATORES DE RISCO}

Os fatores de risco identificados foram: Culpa sobre o diagnóstico da Filha; Sistema Educacional não adaptado; Falta de Suporte do Sistema Público local; Estresse Familiar e a Indisponibilidade Financeira; Julgamento externo preconceituoso sobre o Indivíduo com TEA e o Isolamento Social; Falta de Rede de Apoio e Ausência de pares.

A Falta de rede de apoio e ausência de pares se relaciona com a presença de uma rede de apoio, seja ela especializada ou não, é um dos principais fatores de proteção para promoção da resiliência. A falta desta consequentemente pode se tornar um fator de risco considerável. Percebe-se que, durante os primeiros anos após diagnóstico, na cidade BP os pais de L. não possuíam nenhum tipo de grupo de apoio ou mesmo a presença de outros pais com crianças portadoras de TEA.

V.: Era só eu mesmo. Não tínhamos nenhum grupo de mães assim com autismo. Tinha outras mães atendidas nesse centro da faculdade, mas era por outros motivos, era por timidez, ou por violência, ser agressivo, ser impulsivo, dificuldades alimentares enfim... mas nenhum que era por conta do autismo mesmo. Então não tinha nenhuma mãe lá. 
Para Juliano e Yunes (2014) a eficácia da rede de apoio é demonstrada com a redução dos sintomas psicopatológicos, como por exemplo a depressão ou o sentimento de desamparo. A ausência desta rede implicou em aumento de vulnerabilidade social dos indivíduos frente a uma situação de risco.

Outros dois fatores de riscos complementares são: o Sistema Educacional não Adaptado e a Falta de suporte do sistema público local. Em ambos os fatores o principal responsável pela resolutividade é o governo e suas políticas públicas. As causas da ineficiência destes sistemas estão em um nível muito acima da análise deste trabalho. O que se busca indicar nestes fatores de risco é que a falta ou ineficiência geram impactos que são percebidos pelos pais de uma criança com deficiência.

Logo que ficou constatado o diagnóstico de L., a família teve dificuldades para garantir tratamento de saúde adequado:

V.: Então na época a gente morava em BP e não tínhamos lá, nenhum tratamento específico para autista. O SUS mesmo que começou depois a oferecer alguma coisa, mas era muito precário e nem sabiam do que se tratava.

Segundo as Diretrizes de Atenção à Reabilitação da Pessoa com Transtorno do Espectro do Autismo (TEA) há um fluxograma de atendimento da pessoa com TEA na rede SUS que faz desde o nível da atenção básica à saúde (ou nível 1) até atendimentos hospitalares. Este mesmo documento informa a responsabilidade do SUS de articulação com outros equipamentos sociais e de apoio como CRAS, CAPS, Centros de Convivência, etc. (BRASIL, 2014). Para Santos (2011) é necessário que a família tenha acesso a uma equipe de saúde que a atenda e a mantenha informada a respeito do diagnóstico, diminuindo assim a ansiedade. Isso permite que o indivíduo se sinta amparado, e a informação sobre o diagnóstico pode auxiliar tanto o sujeito autista quanto sua família.

Rocha (2014) conceitua que, para que haja um real suporte social deve-se contemplar: a) suporte instrumental - fornecer instrumentos, sejam eles ajuda financeira, fornecimento de bens e serviços; b) suporte emocional: favorecimento e fortalecimento da rede de apoio e auto estima desta família; c) suporte informativo - permitir conhecimento do que é este transtorno, propiciando que a família consiga criar de métodos de resolução dos problemas; d) suporte confirmativo - garantir a identidade social da família perante a sociedade.

Já no campo de aprendizagem de L., outras dificuldades vinculadas ao TEA podem ser geradoras de frustração direta nos pais.

P: “A educação é o mesmo modelo do século XIX $n e ́$, se fosse 1950 você ia ver a mesma coisa, é carteiras e um professor na frente falando, então hoje você tem uma educação do século XIX professores formados no século XX e alunos do século XXI"

Segundo Brande e Zanfelice (2012, p. 44) “os desafios da inclusão escolar não são conhecidos previamente pelos participantes do ambiente escolar diretores, coordenadores, professores e até mesmo pais". Os desafios só serão conhecidos com a participação e o trabalho colaborativo destes atores ao partilharem suas visões, interpretações e experiências propondo soluções aos problemas decorrentes.

Quando o sistema de ensino não corresponde à expectativa dos pais o resultado é quase sempre de frustração e conflitos por parte dos pais para com a escola ou mesmo com os próprios filhos. Ainda segundo Brande e Zanfelice (2012) tanto a baixa expectativa quanto a alta podem ser prejudiciais ao desenvolvimento. Quando as expectativas são muito baixas em relação ao processo de aprendizagem pode acarretar em um fracasso escolar do filho estigmatizado. Assim como as altas expectativas podem gerar frustrações por exigir demais, seja da escola ou do aluno.
V.: [...] ano passado que a gente conseguiu que ela ficasse retida mais 1 ano, porque a matemática é muito complicada pra ela, muito abstrato. Conta de multiplicação então, até o 3 ela conseguiu, mas depois é muito abstrato, então mesmo antecessor sucessor, isso é... né, ela conta os números até 100 mas antecessor e sucessor, o que vem antes e o que vem depois, ainda é complicado.

Outro fator de risco identificado é a culpa que os pais sentem perante o diagnóstico da filha. Segundo Teixeira (2016) em geral as mães sentem-se responsáveis pelo transtorno da criança, em seu imaginário acreditam que deveriam ter se cuidado mais durante o período de gestação. Ainda segundo esta autora “o sentimento de angústia encontra-se relacionada com a perda da criança sonhada" (TEIXEIRA, 2016, p.19). 
Segundo Smeha e Cezar (2011) o luto da criança idealizada e o nascimento da criança com autismo faz com que os sonhos e as expectativas dos pais se alterem em relação ao filho. Também há um aumento no nível de ansiedade ao se deparar com as incertezas de um novo projeto de futuro diferente do que já havia sido planejado durante a gestação.

No caso dos pais de L. houve durante os primeiros meses de diagnóstico um período de culpabilização $^{2}$ e negação:

V: Então veja, ela vai se desenvolver, pensava assim, estão achando demais dela, ela é normal. Depois você começa a se culpar dizendo que deveria ter estimulado mais, deveria ter feito mais, por isso que ela está assim, a culpa é minha. (...) Quando você tem um diagnóstico você apesar de não saber muito como lidar com isso, você tem que matar essa criança idealizada né! É um termo forte mas você tem que viver um luto de perder aquela criança e aceitar o que você tem. Então o que eu posso fazer para melhorar a vida desta (criança) que eu tenho. Não é uma situação fácil porque você pensa - por quê comigo? Você se culpa achando que - a... eu não deveria ter deixado ela ali na frente da televisão quando eu tava cansada, eu deveria ter chego em casa e ter feito alguma coisa.

Outro fator de risco para a família são as dificuldades financeiras e o estresse familiar. Segundo Rocha (2014) são potenciais formas de estressores familiares: os tratamentos médicos e de terapia dispendiosos seja por tempo ou por custo, agravamento das condições econômicas, dispensas do trabalho para acompanhamento de tratamentos, fadiga constante, sono prejudicado e problemas conjugais. V., durante seu discurso, demonstra que existem dificuldades financeiras no que se refere ao tratamento de L. - em que a médica recomendou sessões de atendimento psicológico 3 vezes por semana. Em sua cidade natal, não havia esse tratamento custeado pelo SUS, assim buscou atendimento particular e percebeu que os custos eram maiores do que a receita da família:

$\mathrm{V}:[\ldots]$ até por questões de custo, porque pagar uma psicóloga 3 vezes por semana, sessões 3 vezes por

\footnotetext{
${ }^{2}$ Segundo Borges (2006) havia uma especulação no meio científico de que crianças autistas fariam parte de famílias cujas mães são distantes emocionalmente de seus filhos chamadas pela expressão "mães geladeiras". Porém essa teoria foi banida nos Estados Unidos a partir de década de 80 e substituída por outras possíveis explicações somato genéticas que deixavam de lado a culpabilização da mãe no desenvolvimento do autismo.
}

semana, ou ela iria falir ou eu (risos). Afinal por mais caridosa que ela fosse, ela também precisa sobreviver e eu tinha mais uma na época para atender - mais uma filha.

Além dos tratamentos solicitados, V. buscava informações nos livros e estudos de caso vinculados ao autismo para adaptar a L., entretanto se deparava com casos fora de sua realidade social gerando um sentimento de angústia muito forte:

V.: Então tem coisas que ajudam bastante, tem outras que você vê, que você lê, e se não tiver bem preparada no final da leitura você corta os pulsos né, aquele... como é o nome daquele livro... "Mãe, me ensina a conversar? "É um livro que... nossa! A mulher é riquíssima, consegue ter vários professores particulares para estimular o filho, e o filho "supera", ele tem uma boa melhora quanto ao autismo e trabalha na empresa da família... Então quer dizer... mas quem que tem... Por isso que eu digo - você termina de ler o livro e não tem recursos para pagar um professor particular, você acha que teu filho nunca vai conseguir nada.

Os últimos fatores de risco identificados são o julgamento externo e preconceituoso sobre o indivíduo com TEA e o isolamento social. Os olhares e os julgamentos das pessoas perante ao filho autista é sentido como um gesto de preconceito segundo Smeha e Cezar (2011). Os autores ainda complementam que, as ofensas dirigidas à filha são sentidas pela mãe como se fosse dirigida a ela mesma.

$\mathrm{V}:[\ldots]$ os outros né, que não sabem que teu filho é espectro autista, acha que ele é mal educado, que ele é... sei lá, birrento né, ah se fosse meu filho eu dava um jeito!

De acordo com Barbosa e Fernandes (2009) os pais de crianças autistas acreditam ter um isolamento social devido ao período de estresse, pela dificuldade de comunicação da criança e pela falta de entendimento pela comunidade.

Pesquisadores: "Vocês têm uma rede de amigos com quem vocês conseguem conversar regularmente?"

P.: "Tem um casal muito próximo que também tem um filho autista $[\ldots]$

Semensato e Bosa (2013) afirmam que os pais de crianças autistas tendem a se relacionar com outros pais de crianças com autismo ou com outras 
necessidades especiais. Entre os motivos estão a aceitação por parte do outro e a proteção de seus filhos contra possíveis conflitos. As autoras destacam que é muito comum o casal ter mais relações virtuais do que presenciais.

\section{ESTRATÉGIAS DE ENFRENTAMENTO}

As estratégias de enfrentamento identificadas foram: capacidade de solucionar problemas, visão positiva da vida, buscar estratégias adaptadas às necessidades dos filhos, aceitar os próprios limites, mudança de cidade e desenvolvimento profissional a partir do contato com o TEA.

A capacidade de solucionar problemas vai ao encontro com o que Folkman e Lazarus (1985) chamam de estratégia de enfrentamento focada no problema, e os autores Rooke e Pereira-Silva (2016) chamam de resolução de problemas, em que o indivíduo procura examinar a situação problema com o objetivo de superá-la.

$\mathrm{V}:[\ldots]$ mas acho que a gente tira forças de algum lugar que você nem sabe que existe, para fazer isso, para dar conta, hoje eu penso - nossa, com as 3 lá... como que fazia? - mas fazia, você dá... você consegue, você busca força de alguns lugares que talvez você nem saiba que tenha, para conseguir dar um suporte, por que ela [L.] precisa me ver bem e me ver forte para também entender que está num lugar tranquilo $[\ldots]$

Observa-se que a mãe se posiciona com uma visão positiva da vida. Os autores Lietz et al. (2016) chamaram de compartilhar significados através de avaliações positivas, em que o indivíduo procura destacar o lado positivo da situação, crescendo pessoalmente através das dificuldades:

V: [...] ah então acho que há superação sim! Ela (L.) tem essas características, mas tem muitas coisas que ela pode melhorar, e superar enfim, até por se tratar de um autismo considerado leve, não é tão comprometido, então acho que ela tem muitas chances de ter uma autonomia ainda maior $[\ldots]$

As estratégias adaptadas às necessidades dos filhos são entendidas por Silva et al. (2009) como $a$ capacidade do pai em responder às necessidades emocionais e fisicas dos filhos. Significa que os pais entendem que essa criança precisa ser amada do jeito que ela é, e a melhor forma de se resolver algum conflito é através do diálogo.

V: [...] não vou sair com uma plaquinha dizendo ela é autista né, que rótulo a gente coloca nos produtos, não nas pessoas, e simplesmente faço o que tenho que fazer, acalmo ela, se for o caso de sentar no chão, eu sento, eu faço o que tem que fazer e quem não gosta que olhe pro outro lado né, não posso fazer nada, e dizer olha, a... eu tenho que pedir desculpas, não, estamos aí a sociedade é essa né? Nós temos é... várias né, pessoas com comportamentos aí que a gente não pode julgar. O que a gente aprende, na verdade, é quando a gente não tinha filhos, a gente olhava essas situações e dizia nossa que se fosse meu filho eu dava um jeito né, a gente sempre tem uma solução, porque é só teoria né, aí depois na prática... Costumo dizer que tem um livro que me representa muito mesmo lá, que eu era uma ótima mãe até ter filhos. A partir do momento que a teoria tem que virar prática, aí então você começa a ver que a chupeta é muito ruim pros dentes, mas acalma a criança. Então dá-lhe chupeta. A L. tem chupeta até hoje.

A estratégia identificada como aceitar os próprios limites se relaciona com o que Rooke e PereiraSilva (2016) chamam de aceitação de responsabilidade. Entende-se que o indivíduo compreende os próprios limites quanto a situação problema, e procuram reorganizá-la, de uma forma que todos se sintam bem. Como você ser visto no trecho da entrevista abaixo em que há uma tentativa que mudança, reorganização após o diagnóstico para que toda a família funcione melhor.

$\mathrm{V}:[\ldots]$ Não é uma situação fácil porque você pensa: por quê comigo? Você se culpa achando que - a... eu não deveria ter deixado ela ali na frente da televisão quando eu tava cansada, eu deveria ter chego em casa e ter feito... - Então você se culpa, você tem que passar pela parte da negação - não ela não é, ela é normal, veja ela tá falando, só com ela, mas ela tá falando né... Só depois você vê que a culpa não é de ninguém, se isso aconteceu agora a gente tem que lutar com a família toda, ou quem você quiser mobilizar para melhorar $[\ldots]$

A estratégia de enfrentamento mudança de cidade vai ao encontro com o que Roberto e Moleiro (2015) falam sobre ir a procura de um objetivo que melhore as condições de vida atuais. As autoras explicam que, muitas vezes, o fator socioeconômico estimula mudança de trajetória da pessoa, principalmente 
quando não há recursos suficientes no local. Com isso, o indivíduo procura outros lugares que ofereçam os recursos necessários para o seu desenvolvimento. V. residia em BP, e como a cidade não tinha os recursos necessários para o atendimento de sua filha L., a família decidiu mudar de cidade.
V.: Ele achou um apartamento que coubesse as coi- sas e achou vaga para as meninas na escola, ficou de madrugada na fila, enfim, como todo mundo fica, em um revezamento familiar, um pouco fica o irmão, um pouco fica outro, até dar certo, e viemos então em dezembro para cá.

A estratégia de enfrentamento desenvolvimento profissional a partir do contato com o TEA diz respeito ao que Campos e Martins (2012) explicam sobre a educação especial inclusiva. Entende-se que a escola contém uma diversidade de indivíduos, que devem ser respeitados dentro de suas diferenças. Assim, para que inclusão ocorra, deve-se adaptar métodos às necessidades individuais, para que o indivíduo seja de fato respeitado em sua singularidade e de fato incluído no sistema educacional. Observa-se que V. usa de seus conhecimentos como mãe de uma criança autista para crescer profissionalmente, atribuindo um valor emocional a sua área de atuação.

V.: Todo aluno aprende de uma forma diferente, neurotípicos né, aprendem de forma diferente, mas a gente quer ensinar todo mundo igual, não tem esse respeito da forma de... às vezes só falando ele não vai entender, tenho que passar algo escrito, às vezes eu tenho que mudar a forma com que estou falando, não pode ser tão genérico. Então isso eu vejo que ter a L. como filha, é... me ajudou como professora, sabe, porque aí eu consigo, mesmo não tendo alunos autistas né, e...nós não temos nenhum laudo autista mas nós temos laudo de dislexia, laudo de transtorno de déficit de atenção, enfim, é como a maioria das escolas tem essas dificuldades com os neurotípicos né, mas também aí eu dou, consigo variar um pouco a minha prática pensando se fosse um aluno autista né. Se fosse um aluno autista e eu coloco lá um slide que tem um bichinho que fica pulando, ele não vai prestar a atenção em nada que eu to falando lá na frente e vai ficar só olhando o bichinho pulando. Tenho que ter cuidado com algumas coisas que pra alguns serve de estímulo, pra outros serve de distração, então quem tem déficit de atenção vai ficar olhando o bichinho, e vou falar aqui até amanhã e ele não vai estar nem aí, então algumas coisas que é... eu acho que melhora muito mais. (...) Com ela (L.) a gente tem que fazer de uma outra forma, então a gente acaba fazendo de uma outra forma, de uma forma mais clara pra todas.

Ao realizar a entrevista com os pais de L., foi possível observar que a mãe, $\mathrm{V}$. respondeu ao maior número de perguntas. Porém, mesmo que o pai falasse menos que a mãe, ele se mostrou engajado. Os entrevistadores conseguiram compreender que apesar das dificuldades encontradas, a família estava unida e de acordo com as escolhas feitas para auxiliar no desenvolvimento de L. Apesar dos fatores de risco encontrados, os fatores de proteção e as estratégias de enfrentamento superam as adversidades encontradas. É possível afirmar que essa é uma família que possui comportamentos resilientes.

\section{CONSIDERAÇÕES FINAIS}

A presente pesquisa teve como objetivo levantar dados e compreender como os fatores de risco e os fatores de proteção dificultam e facilitam, respectivamente, o desenvolvimento de resiliência em pais de uma criança diagnosticada com o Transtorno do Espectro Autista. Além disso, também foi proposta a descrição e o entendimento de como a família enfrentou as dificuldades (estratégias de enfrentamento) que apareceram após o diagnóstico da filha.

Foi observado que há muitas dificuldades (fatores de risco) principalmente no momento do diagnóstico da criança, sobre como os outros irão julgar a criança e/ou os pais, a falta de recursos e profissionais na área da reabilitação da criança autista e o isolamento dos pais e da criança. (BARBOSA; FERNANDES, 2009)

No que se refere aos fatores de proteção, observou-se que estar em uma região (no caso Curitiba) com recursos e profissionais adequados à reabilitação da criança autista e de sua família auxilia no processo de promoção de resiliência dos pais. Ter expectativas de encontrar pessoas com problemas semelhantes e um relacionamento familiar integrado também auxiliam no processo de alívio do problema. Além disso, foi possível constatar que a percepção por parte dos pais do desenvolvimento de sua filha influenciam positivamente no desenvolvimento de resiliência. Tudo o que foi descrito anteriormente se referem ao apoio 
social, que Juliano e Yunes (2014) afirmam ser um forte fator promotor de resiliência.

Quanto às estratégias de enfrentamento, a capacidade de solucionar problemas, de aceitar os próprios limites, de procurar se adequar às necessidades da filha e se mudar para uma cidade com mais recursos foram essenciais para que a família conseguisse superar os fatores de risco e se desenvolvessem de forma resiliente, isto é, crescendo a partir das dificuldades. (BARBOSA; OLIVEIRA, 2008)

Vale ressaltar que essa pesquisa teve limitações, por ser um estudo de caso, não há dados estatísticos que permitam generalizar esses resultados, sendo esse entendimento limitado apenas ao caso estudado. Dessa forma, sugere-se que estudos futuros procurem dados qualitativos e quantitativos que se relacionem com o desenvolvimento de resiliência na família.

\section{REFERÊNCIAS}

AMERICAN PSYCHIATRIC ASSOCIATION. Manual diagnóstico e estatístico de transtornos mentais: DSM V. American Psychiatric Association; tradução: Maria Inês Corrêa Nascimento et al. 5. ed. Porto Alegre: Artmed, 2014.

BARBOSA, A. J. G.; OLIVEIRA, L. D. Estresse e enfrentamento em pais de pessoas com necessidades especiais. Psicologia em Pesquisa, UFJF, v. 2, n. 02, p. 3650, 2008. Disponível em: < http://pepsic.bvsalud.org/pdf/ psipesq/v2n2/v2n2a05.pdf $>$. Acesso em 15 mar 2019.

BARBOSA, M. R. P.; FERNANDES, F. D. M. Qualidade de vida dos cuidadores de crianças com transtorno do espectro autístico. Revista da sociedade Brasileira de Fonoaudiologia, São Paulo, v. 14, n. 4, p. 482-486, 2009. Disponível em: < https://bdpi.usp.br/bitstream/handle/ BDPI/9167/art_BARBOSA_Qualidade_de_vida_dos_ cuidadores_de_criancas_2009.pdf? sequence $=1>$. Acesso em 15 mar 2019.

BARDIN, L. Análise de conteúdo. Editora: Edições 70, Portugal, 1994.

BORGES, T. P. Considerações sobre o autismo infantil. Mental, Barbacena, v. 4, n. 7, p. 137-146, nov. 2006. Disponível em: http://pepsic.bvsalud.org/scielo. php?script=sci_arttext\&pid=S167944272006000200009\&1 ng=pt\&nrm=iso . Acesso em 16 mar 2019.

BRANDE, A. C.; ZANFELICE, C. C. A inclusão escolar de um aluno com autismo: diferentes tempos de escuta, intervenção e aprendizagens. Revista de educação especial, Santa Maria, v. 25, n. 42, p. 43-56, jan./abr. 2012. Disponível em: <http://dx.doi.org/10.5902/1984686X3350>. Acesso em 19 mai 2017.
BRASIL. MINISTÉRIO DA SAÚDE. SECRETARIA DE ATENÇÃO À SAÚDE. Diretrizes de Atenção à Reabilitação da Pessoa com Transtorno do Espectro do Autismo (TEA) Brasília: Ministério da Saúde, 2014. Disponível em $<$ http:// bvsms.saude.gov.br/bvs/publicacoes/diretrizes_atencao reabilitacao_pessoa_autismo.pdf>. Acesso em 19 mai 2017.

CAMPOS, S. M. G; MARTINS, R. M. L. A inteligência emocional em professores de educação especial da região de Viseu. Millenium, n. 43, p. 7-28, 2012. Disponível em $<$ http://revistas.rcaap.pt/millenium/article/view/8177>. Acesso em 19 mai 2017.

FOLKMAN, S.; LAZARUS, R. S. (1985). If it changes it must be a process: Study of emotion and coping during three stages of a college examination. Journal of Personality and Social Psychology, v. 48, n. 1, 150-170. Disponível em: < https://doi.org/10.1037/0022-3514.48.1.150 >. Acesso em 15 mar 2019.

GADIA, C. A.; TUCHMAN, R.; ROTTA, N. T. Autismo e doenças invasivas de desenvolvimento. Jornal de Pediatria, v. 80, 2004. Disponível em <http://www. scielo.br/scielo.php? script $=$ sci_arttext\&pid $=\mathrm{S} 0021$ $75572004000300011 \& \operatorname{lng}=$ en\&nrm $=$ iso $>$. Acesso em 19 mai 2017.

JULIANO, M. C. C.; YUNES, M. A. M. Reflexões sobre a rede de apoio social como mecanismo de proteção e promoção de resiliência. Ambiente \& Sociedade, São Paulo, v. 17, n. 3, p. 135-154, 2014. Disponível em <http://www. scielo.br/scielo.php?script=sci_arttext\&pid=S1414-753X20 $14000300009 \& \operatorname{lng}=\mathrm{en} \& \mathrm{nrm}=\mathrm{iso}>$. Acesso em 19 mai 2017.

LEAL, A. L.; RÖHR, F.; JUNIOR, J. P. Resiliência e espiritualidade: algumas implicações para a formação humana. Conjectura, v. 15, n. 1, p. 11-24, 2010. Disponível em <http://www.ucs.br/etc/revistas/index.php/conjectura/ article/view/173/164>. Acesso em 19 mai 2017.

LIETZ et al. (2016). Cultivating Resilience in Families Who Foster: Understanding How Families Cope and Adapt Over Time. Familiy Process, v. 55, n. 4, 660-672. Disponível em: $<$ https://doi.org/10.1111/famp.12239>. Acesso em 15 mar 2019.

NORONHA, M.G.R.C.S. et al. Resiliência: nova perspectiva na Promoção da Saúde da Família? Ciência \& Saúde Coletiva, v. 14, n. 2, p. 497-506, 2009. Disponível em < http://dx.doi.org/10.1590/S1413-81232009000200018>. Acesso em 18 mar 2019.

ORGANIZAÇÃO MUNDIAL DA SAÚDE. CID-11 Classificação Estatística Internacional de Doenças e Problemas relacionados à Saúde. São Paulo: Universidade de São Paulo, 2018.

POLETTO, M.; KOLLER, S. H. Contextos ecológicos: promotores de resiliência, fatores de risco e de proteção. Estudos de Psicologia, Campinas, v. 25, n. 3, p. 405-416, 
2008. Disponível em <http://dx.doi.org/10.1590/S0103166X2008000300009>. Acesso em 19 mai 2017.

POLETTO, M.; WAGNER, T. M. C.; KOLlER, S. H. Resiliência e Desenvolvimento Infantil de Crianças que Cuidam de Crianças: Uma Visão em Perspectiva. Psicologia: Teoria e Pesquisa, Brasília, v. 20 n. 3, p. 241-250, Set-Dez 2004.

ROBERTO, S.; MOLEIRO, C. Processos de resiliência em migrantes: narrativas biográficas de brasileiros em Portugal. Psicologia em Estudo, Maringá, v. 20, n. 2, p. 295-307, 2015. Disponível em <http://www.redalyc.org/ pdf/2871/287143251014.pdf>. Acesso em 19 mai 2017.

ROCHA, M. I. P. Resiliencia, Suporte Social e Stress Parental em Familias de Crianças com Necessidades Educativas Especiais. 2014. 134 f. Dissertação para a obtenção do grau de Mestre em Psicologia da Educação - Universidade do Algarve, Faro, 2014.

ROOKE, M. I.; PEREIRA-SILVA, N. L. Indicativos de resiliência familiar em famílias de crianças com síndrome de down. Estudos de Psicologia, Campinas, v. 33, n. 1, p. 117126, 2016. Disponível em <http://dx.doi.org/10.1590/1982027520160001000012 >. Acesso em 19 mai 2017.

SANTOS, A. F. A resiliência e sua forma de promoção em famílias que convivem com a doença crônica. 39f. Dissertação (Especialização em Atenção Básica em Saúde da Família). Universidade Federal de Minas Gerais. 2011.

SILVA, M. R. S. et al. Processos que sustentam a resiliência familiar: um estudo de caso. Texto Contexto em Enfermagem, Florianópolis, v. 18, n. 1, p. 92-99, 2009. Disponível em $<$ http://www.scielo.br/pdf/tce/v18n1/v18n1a11>. Acesso em 19 mai 2017.

SEMENSATO, M. R.; BOSA, C. A. Relatos de pais de crianças com autismo sobre a rede de apoio formal: aspectos da elaboração parental do diagnóstico. Revista Educação Especial, v. 26, n. 47, p. 651-664, 2013. Disponível em $<$ http://dx.doi.org/10.5902/1984686X9687>. Acesso em 19 mai 2017.

SMEHA, L. N.; CEZAR, P. K. A vivência da maternidade de mães de crianças com autismo. Psicologia em estudo, Maringá, v. 16, n. 1, p. 43-50, 2011. Disponível em <http:// dx.doi.org/10.1590/S1413-73722011000100006>. Acesso em 19 mai 2017.

SOUSA, J. E. P. Contextos ecológicos: promotores de resiliência, fatores de risco e de proteção. Saber (e) Educar, v. 11, p. 41-47, 2006. Disponível em <http://dx.doi. org/10.1590/S0103-166X2008000300009>. Acesso em 19 mai 2017.

TAMANAHA, A. C.; PERISSINOTO, J.; CHIARI, B. M. Uma breve revisão histórica sobre a construção dos conceitos do Autismo Infantil e da síndrome de Asperger. Revista da Sociedade Brasileira de Fonoaudiologia, v.13, n.3, p. 296-
269, 2008. Disponível em <http://www.scielo.br/pdf/rsbf/ v13n3/a15v13n3.pdf>. Acesso em 18 mar 2019.

TEIXEIRA, A. V. B. Resiliência e Stress em Pais de Crianças com Perturbações do Espectro do Autismo. 2016. 62 f. Dissertação para obtenção do grau de Mestre em Psicologia da Educação - Universidade do Algarve, Faro, 2016.

YIN, R. S. Estudo de Caso: Planejamento e Métodos. 5. ed. edição. Porto Alegre: Bookman, 2015. 